\title{
Human Homosexuality: A Paradigmatic Arena for Sexually Antagonistic Selection?
}

\author{
Andrea Camperio Ciani ${ }^{1}$, Umberto Battaglia ${ }^{1}$, and Giovanni Zanzotto ${ }^{2}$ \\ ${ }^{1}$ Dipartimento di Filosofia, Sociologia, Pedagogia e Psicologia Applicata, Università di Padova, \\ 35100 Padova, Italy \\ ${ }^{2}$ Dipartimento di Psicologia Generale, Università di Padova, 35100 Padova, Italy \\ Correspondence: andrea.camperio@unipd.it
}

Sexual conflict likely plays a crucial role in the origin and maintenance of homosexuality in our species. Although environmental factors are known to affect human homosexual (HS) preference, sibling concordances and population patterns related to HS indicate that genetic components are also influencing this trait in humans. We argue that multilocus, partially $\mathrm{X}$ linked genetic factors undergoing sexually antagonistic selection that promote maternal female fecundity at the cost of occasional male offspring homosexuality are the best candidates capable of explaining the frequency, familial clustering, and pedigree asymmetries observed in HS male proband families. This establishes male HS as a paradigmatic example of sexual conflict in human biology. HS in females, on the other hand, is currently a more elusive phenomenon from both the empirical and theoretical standpoints because of its fluidity and marked environmental influence. Genetic and epigenetic mechanisms, the latter involving sexually antagonistic components, have been hypothesized for the propagation and maintenance of female HS in the population. However, further data are needed to truly clarify the evolutionary dynamics of this trait.

Sexual conflict, the general theme of this colSlection, has emerged in the last decades as a main research topic in evolutionary biology. Its possible ubiquity and key role have become clear in many phenomena, from speciation to genetic diversity maintenance in populations, sexual phenotypic dimorphism, asymmetric mating and parenting strategies, antagonistic coevolution, and others (Bonduriansky and Chenoweth 2009; Rice et al. 2013; see also Gavrilets 2014). A most interesting example of sexual conflict is given by homosexual (HS) behavior and mate preference in humans, a topic whose societal impact is widely felt at present.
Homosexuality is not confined just to our species, but is also occasionally present in numerous animals (Bagemihl 1999; Sommer and Vasey 2006), with permanent, long-term samesex pair bonding having been reported in some birds and ungulates (Bagemihl 1999; Ngun et al. 2011). The presence of not solely sporadic and opportunistic HS behavior has also been observed in nonhuman primates, which suggests our hominid ancestry might also have had HS individuals (Vasey 1995).

The main evolutionary questions about HS in our species do not concern occasional HS behavior, which might have, in various con-

Editors: William R. Rice and Sergey Gavrilets

Additional Perspectives on The Genetics and Biology of Sexual Conflict available at www.cshperspectives.org

Copyright (C) 2015 Cold Spring Harbor Laboratory Press; all rights reserved; doi: 10.1101/cshperspect.a017657 Cite this article as Cold Spring Harb Perspect Biol 2015;7:a017657 
A. Camperio Ciani et al.

texts, a fitness advantage (Bagemihl 1999), but rather refer to the origin, prevalence, frequency, population distribution, maintenance, and selective values of long-term HS preference. First and foremost, the stable permanence of HS in human populations constitutes a puzzling "Darwinian paradox" for any putative genetic loading in this apparently detrimental trait. Even a partial genetic predisposition would seemingly contradict the assumption that natural selection will progressively eliminate any genetic factors contributing to reduce individual fitness. Understanding HS is not only a challenging scientific conundrum related to the evolutionary conflicts between sexes; because of the estimated prevalence of this trait involving a nontrivial fraction of the human population (see below), these issues also potentially concern several hundred million people.

Since the 1990s, the role of biological factors, both genetic and nongenetic, has come to light in relation to HS (see Camperio Ciani et al. 2004; Gavrilets and Rice 2006; Jannini et al. 2010). The possible genetic components influencing human HS have since been explored empirically and theoretically. However, we emphasize at the outset that a number of environmental factors (zygotic, prenatal, and postnatal) are known to affect HS preference in either or both genders, such as maternal stress, mother estrogen-progestinics assumption during fetal development, fraternal birth order, as well as environmental and social influences (see Ward and Weisz 1980; Dörner et al. 1983; Whisman 1996; Rosenbluth 1997; Stein 1997; Blanchard 2001; Garcia-Falgueras and Swaab 2010; Långström et al. 2010; Balthazart 2011; Mychasiuck et al. 2012). Thus, genetic components can never be considered as exclusive determinants of HS, and they should always be interpreted as acting within the frame of an environmental background that may also significantly contribute to same-sex preference in individuals (Balthazart 2011).

Besides environmental effects, incomplete penetrance and variable expressivity are also expected for any complex behavioral traits with less-than-Mendelian ratios in pedigrees such as HS. Although these factors contribute to blur the phenotypic expression of any genetic basis on behavior (Plomin et al. 2001), for HS they do not entirely obfuscate the recognizable effect of genetic influences and polymorphism in human populations.

Population genetics, demographic distributions, and biometric properties are increasingly recognized as main tools needed for the understanding of complex traits for which (epi)genetic roots are hypothesized (Sham 2001; Boomsma et al. 2002; Lynch 2007). It is important to stress that population patterns should provide a set of constraints against which any propagation or maintenance hypotheses for HS-related genetic factors must be explicitly tested, as lacking such information, any theoretical results and predictions remain largely impossible to falsify. Thus, the efforts to explain HS should consider a series of specific empirical aspects that this trait presents in human populations, namely: (1) low prevalence and stable, universal distribution; (2) familial aggregation; (3) specific distribution within families; and (4) possible balancing fecundity effects associated with the traits. We summarize, below, the main findings concerning such population patterns. We observe that some general trends emerge in the replications by independent research groups, with data collected through diverse methods and protocols, but much work is still necessary, especially in relation to female HS.

A number of hypotheses have been posited in the evolutionary investigation of male HS, whose selection routes have been studied in more detail than for female HS. Below, we report on the results regarding the likely evolutionary mechanisms for male HS (Camperio Ciani et al. 2004, 2008; Gavrilets and Rice 2006). As we will discuss, research in this direction has indicated that among the studied mechanisms, sexually antagonistic selection, an important aspect of sexual conflict, appears the best hypothesis, which can correctly account for the available population data related to male HS. Population surveys and mathematical modeling have thus concurred to establish male HS as a paradigmatic example of sexual conflict in human biology. 
Human Homosexuality

In contrast, female HS remains to this day a much more elusive phenomenon from both the empirical and theoretical standpoints. Several marked differences exist, which make female HS, in many ways, unlike its counterpart in males. Some of the dissimilarities appear fully elucidated, others await further work for clarification. For instance, environmental effects are known to play a stronger role in female HS, especially the shared-environmental influences, which are virtually absent in male HS (Bailey et al. 2000; Långström et al. 2010). A further obstacle lies in the fact that it is not clear whether HS in females has entailed a nontrivial fecundity reduction in the evolutionary past, as opposed to present times. The coexistence of HS with other powerful behavioral patterns may have masked the effects of any genetic propensity to HS behavior in females with its possible implied reduced fitness. This could pose difficulties for thoroughly ascertaining the evolutionary dynamics of this trait in human populations.

Nonetheless, genetic and epigenetic mechanisms (Pattatucci and Hamer 1995; Rice et al. 2008) have been hypothesized for the evolutionary dynamics of female HS. In particular, to account for some peculiar patterns observed within the families of HS females, it has been hypothesized that sexual conflict be at play through (epi)genetic factors known as sexually antagonistic zygotic drive, which might contribute to the transmission (Rice et al. 2008; see also Friberg and Rice 2014). This would posit sexual conflict as a basic selection mechanism also for HS in females. Such models, however, have yet to be fully tested against well-established data on the population patterns connected to female HS, which also remain, to this day, relatively scarce.

For both sexes, and especially for females, the current evidence on population data limits, but does not rule out, the influence of other (epi)genetic factors on HS, perhaps unrelated to sexual conflict. Their possible action, however, falls within a more opaque and stochastic background, to which also environmental effects largely contribute, and in which clear patterns have not yet been properly identified, neither for male nor for female HS.

\section{EMPIRICAL EVIDENCE ON POPULATION PATTERNS RELATED TO HS IN HUMAN POPULATIONS}

\section{Stability of HS in Human Populations}

Homosexuality is a stable trait that has been documented in human societies over several millennia (Herdt 1997; Nash 2001; Crompton 2006). It has been confirmed through archaeological evidence that both female and male HS occurred also prehistorically and cannot be considered a product of modern times (Ruse 1988; Herdt 1997; Nash 2001).

\section{Trait Prevalence and Features}

HS is present in almost all human populations, with relatively low frequency, or prevalence (Diamond 1993; but see Hewlett and Hewlett (2010) and Barthes et al. (2013) for cases of presumed absence of HS in some cultures). The prevalence of HS behavior may largely vary over time and geographical region. Population-based surveys have suggested prevalences of $\sim 2 \%-9 \%$ for lesbians, compared with $0.5 \%-15 \%$ for gays, with a more general agreement on $2 \%-7 \%$ in most Western countries for both genders (Bell and Weinberg 1978; Bailey and Benishay 1993; Diamond 1993; Johnson et al. 1994; Sell et al. 1995; Herek et al. 1997, 1999; Bullough 1998; Bailey et al. 2000; Bogaert 2004; Camperio Ciani et al. 2004, 2009; Butler 2005; Caceres et al. 2006; Wright 2009; Hewlett and Hewlett 2010). However, prejudice, persecution, homophobia, and religious orthodoxy might induce individuals not to reveal, even in anonymous questionnaires, their own sexual preference, creating an "obscure number" of individuals who will never explicitly disclose such information (Savin-Williams 2006; Camperio Ciani and Battaglia 2014). Also, sampling problems affect surveys on sexual preference, as well as the location, whether urban or rural, and the method used, such as Internet surveys, etc. The above figures should thus be considered as fairly uncertain estimates producing no final consensus.

Better ascertained is the fact that the distribution of HS preference on the Kinsey scale is 
A. Camperio Ciani et al.

polarized and U-shaped for males, with a relative higher frequency of complete or almost complete heterosexuals or homosexuals and relatively few bisexuals. In contrast, females show, on the same scale, a progressively declining frequency from complete heterosexuality toward complete homosexuality (Pillard and Weinrich 1986; Bailey and Pillard 1991; Pattatucci 1998; Bailey et al. 2000; Camperio Ciani et al. 2009). Bisexuality is, thus, more common in women than in men (Bailey and Pillard 1991; Hamer et al. 1993; Whitman et al. 1993; Pattatucci and Hamer 1995; Diamond 2008; Camperio Ciani et al. 2009; Alanko et al. 2010). Also, HS females seem more flexible in response to shared-environmental factors compared with HS males (Bailey et al. 2000; Rahman 2005; Lippa 2006; Alanko et al. 2010; Långström et al. 2010). Females might express sexual preference for females also because of feminist, political, egalitarian reasons, in addition to being driven to HS by erotic or emotional attraction (Whisman 1996; Rosenbluth 1997; Stein 1997). More females than males appear to have switched from heterosexual to HS preference, even after a satisfactory period of heterosexuality (Blumstein and Schwartz, 1976), and vice versa. None of these patterns are common in HS men. The sexuality of males becomes relatively fixed by young adulthood, contrary to females who may maintain their sexual fluidity well into adulthood (Blumstein and Schwartz 1977; Rust 1992; Bailey and Benishay 1993; Bailey et al. 1993; Pattatucci and Hamer 1995; Esterberg 1997; Baumeister 2000).

Family Clustering and Asymmetries in Trait Frequency

Almost all studies have shown that both male and female HS are not evenly distributed within the population, but rather run in families (Bailey and Zucker 1995; Pattatucci and Hamer 1995; Pattatucci 1998; Bailey et al. 2000; Kendler et al. 2000; Långström et al. 2010; Camperio Ciani and Pellizzari 2012).

In females, HS concordance probability for sisters was found to be higher than chance (Bailey and Benishay 1993; Bailey et al. 1993; Patta- tucci and Hamer 1995; Pattatucci 1998). Also, Pattatucci and Hamer (1995) recorded elevated rates of nonheterosexuality in four classes of female relatives of lesbian probands: sisters, daughters, nieces, and female cousins through a paternal uncle. However, new preliminary data suggest elevated rates of HS in all female classes of lesbian probands' relatives, in both parental lines (Camperio Ciani et al. 2014a).

Male HS also runs in families, and gay probands show elevated frequencies of HS brothers, cousins, and uncles, mostly in the maternal line (see also the section Asymmetries in Pedigrees), and do not show more female HS in their pedigrees if compared with heterosexual males (Hamer et al. 1993; Camperio Ciani et al. 2004; Blanchard and Lippa 2007; Rahman et al. 2008; Iemmola and Camperio Ciani 2009). Also, Pillard and Weinrich (1986) found that sisters of male HS are not more likely to be lesbian than the sisters of heterosexual males.

These data indicate that male and female HS orientation clusters in families, but in a different manner in the two genders.

\section{Fecundity of Male HS}

HS males reproduce significantly less than heterosexual males, an evolutionary cost that has been confirmed by several studies (Bell and Weinberg 1978; Iemmola and Camperio Ciani 2009; Rieger et al. 2012). The average presentday fecundity of HS males as a population's subgroup, normalized to the fecundity of heterosexuals, has been quantitatively estimated in Western European countries or North America approximately between 0.2 and 0.7 (Moran 1972; Bell and Weinberg 1978; Camperio Ciani et al. 2008). This interval is wide enough that it may be reasonably assumed to encompass also the reduced fitness of male HS under the varying circumstances of our evolutionary past.

\section{Fecundity of Female HS}

Modern Western female HS show low normalized fecundity, estimated below 0.5 (Pattatucci and Hamer 1995; Gates et al. 2007; Patterson and Riskind 2010; Camperio Ciani et al. 
2014a). Such strongly reduced value may be a result of, not only to same-sex attraction or choice, but also to female HS being victims of homophobia, prejudice, and laws against samesex households. Indeed, recent investigations appear to indicate that more liberal laws for same-sex couples, maternity through alternative means, such as in vitro fertilization, and adoption by same-sex couples, might be responding to a maternal drive to motherhood in HS females (Butler 2005; Patterson and Riskind 2010; Farr and Patterson 2013), possibly raising, in turn, also their fecundity. Because maternal drive arises later in adulthood than erotic attraction, it has been predicted that fecundity in lesbians should grow later in age, a fact that has partly been confirmed by Farr and Patterson (2013). Other recent data, however, question the latter conclusion, showing low fecundity values below 0.2 also in aged Italian lesbians living in contemporary relatively liberal environments (Camperio Ciani et al. 2014a).

In contrast, a low or very low fecundity of female HS in the past might be questionable for multiple reasons: (1) patriarchal societies, (2) sexual flexibility, (3) strong maternal drive, and (4) as a counterstrategy against male family desertion and infanticide. The convergent effects of such causes might have eliminated any fecundity reduction in female HS (caused by same-sex attraction) in our evolutionary past. The vast majority of past societies were patriarchal and females have been ruled, traded and exchanged, destined to opportunistic marriages, and forced to reproduce, with substantial indifference to their sexual preferences (Kraemer 1991; Bar On 1994; Vrissimtzis 1997; Apostolou 2013). Also, an inner drive to nurture offspring may often surpass one's own other needs at a physiological, hormonal, and behavioral level, including HS preference (Mezey 2008). Furthermore, maternal drive is independent of sexual orientation, and before in vitro fertilization, attaining fecundity in response to a growing maternal instinct might have been possible also through natural means by accepting to reproduce with the other sex (Mezey 2008; Patterson and Riskind 2010). Contrary to males, in which a lack of sexual attraction makes fertilization physiologically demanding, females could use sexuality more widely to opportunistically achieve fertilization, independently of explicit erotic attraction to males (Baumeister 2000). Finally, lesbian behavior might have enhanced same-sex pair bonds to adequately nurture offspring, and to protect it in case of male desertion of the family, which may have been universally common through human history (Eubank 1916; Colcord 1919; May 1988; Lamb 2004). A lesbian strategy to exclude the intrusion in the household of a new potentially infanticidal male might have produced strong fitness benefits on the female side. Recent studies show that female counterstrategies to avoid male infanticide in humans have been powerful in determining the adaptive value of a trait (de Waal and Gavrilets 2013; Lukas and Clutton Brock 2013; Opie et al. 2013). All of the above causes might have significantly contributed to balance past HS females' lack of erotic attraction to males, increasing their fecundity compared with the present day, to possibly match the average heterosexual fecundity. This may have contributed to making female HS an evolutionarily neutral trait (see the section Candidate Selection Mechanisms for Female HS).

\section{Asymmetries in Pedigrees}

In male HS, empirical observations indicate the existence of characteristic "pedigree asymmetries" concerning female fecundity within the gay probands' families. Camperio Ciani et al. (2004) found that, in general, female maternal relatives of HS males have significantly higher fecundity than female maternal relatives of heterosexual males, and this difference was not found among female paternal relatives. Specifically, increased female fecundity regards mothers (with normalized fecundity, $\alpha>1.2$ ), aunts, and grandmothers in the maternal line of male HS, as well as male bisexuals (Camperio Ciani et al. 2009; Jannini et al. 2010; Camperio Ciani and Pellizzari 2012). These findings were replicated in a number of studies (see Blanchard and Lippa 2007; Rahman et al. 2008; Iemmola and Camperio Ciani 2009; VanderLaan and Vasey 2011; Blanchard 2012; Rieger et al. 2012). It 
A. Camperio Ciani et al.

was also found that mothers and aunts of male HS recorded fewer abortions, fewer gestational and parturition complications, and higher extraversion (Camperio Ciani et al. 2012). It should be noted, however, that other investigators have reported a generalized fecundity increase in other members in the pedigrees of male HS probands, independent of the maternal or paternal line (King et al. 2005; Schwartz et al. 2010), and Rieger et al. (2012), based on the dataset by Schwartz et al. (2010), found excess fecundity in brothers of male HS. Subsequently, the data by Schwartz et al. (2010) were reanalyzed by Camperio Ciani and Pellizzari (2012), highlighting, also in this dataset, a previously unnoticed larger maternal-line female fecundity. Finally, a population dynamics analysis of male HS (see Camperio Ciani et al. 2008 and the section Genetic Models for Male HS below), showed a rather singular, previously unconsidered, fecundity increase in paternal aunts of heterosexuals, as compared with homosexuals. This effect was later detected in a reanalysis of empirical data by Camperio Ciani and Pellizzari (2012).

For female HS, Pattatucci and Hamer (1995) did not report, in the pedigrees, any significant, possibly asymmetric, fecundity increases as mentioned above regarding male HS. However, preliminary data on families of HS females show they have a larger pedigree size (more relatives in the three antecedent generations) compared with control heterosexual females' families, indicating, if confirmed, a general fecundity increase (Camperio Ciani et al. 2014a). This effect is particularly evident in the subsample of families with at least one lesbian member other than the proband, which show an excess of males in the paternal line versus the maternal line.

\section{Fraternal Birth Order Effect}

Several studies have found that having older biological brothers (not sisters) increases the probability of HS in later-born males (Blanchard and Bogaert 1996; Blanchard 2001, 2004; Cantor et al. 2002). This is a maternal influence, referred to as the fraternal birth order
(FBO) effect, which has been hypothesized to relate to a progressive immunization of the mother to successive male fetus exposure (Blanchard 2004; Bogaert and Skorska 2011). The effect holds also if the siblings are raised in separate households, whereas step- or adoptive brothers have no effect on sexual orientation (Bogaert 2006). Notably, in case of later-born monozygotic (MZ) twins, the FBO could contribute to increasing the HS concordance rates in males (Camperio Ciani et al. 2004). However, not all researchers confirmed a significant FBO effect in male HS (Frisch and Hviid 2006; Blanchard and Lippa 2007; see also LeVay 2011, for questions on the FBO). No birth order effect has been reported in female HS (Ellis and Blanchard 2001; Blanchard 2004). McConaghy et al. (2006) have suggested that both females and males with HS feelings are most likely born later, not for biological reasons, but rather because of social processes; however, this hypothesis ignores the evidence on adoptive and separated siblings.

Twin Studies and Estimates of Genetic Heritability

Empirical evidence from family studies, comparing pairs of adoptive brothers, biological brothers, dizygotic (DZ), and MZ twins, have shown that the probability of HS sibling concordance in all such classes to progressively increase if the proband is HS, which strongly suggests the presence of a genetic influence (Kendler et al. 2000; Plomin et al. 2001; Posthuma et al. 2003). Also, the much lower rate of HS concordance between adopted sisters as compared with biological sisters is in line with the genetic heritability paradigm (Bailey et al. 1993; Plomin et al. 2001; Posthuma et al. 2003).

Earlier heritability estimates for HS used the values of either pairwise or probandwise HS concordance rates in $\mathrm{MZ}$ and $\mathrm{DZ}$ twins. Studies with small sample sizes, with inherent ascertainment bias, found either high pairwise concordance of HS between $40 \%$ and $75 \%$, both in male and female MZ twins (Pillard and Weinrich 1986; Kendler and Eaves 1989; Bailey and Pillard 1991; Bailey et al. 1993; Withman et al. 
1993; Hershberger 1997), or very low rates (Eckert et al. 1986; Hershberger 1997). Subsequently, it was clarified (McGue 1992) that the probandwise concordance is the most adequate metric to interpret individual probabilities when comparing different studies because it better accounts for familiar risk-probability factors, different ascertainment biases, and different population prevalence rates. Moreover, the more recent population-wide twin studies on sexual orientation have also provided estimates on the heritability of homosexuality through the identification of sample variance components, that is, additive genetics, common (shared) environment, and unique (nonshared) environment (ACE model) (Martin et al. 1997), rather than the sole concordance, hence, providing further results on heritability in homosexuality.

Thus, in a population-wide twin study in Australia, Bailey et al. (2000) reported probandwise HS concordance values $20 \%-37 \%$ for males and 24\%-30\% for females, depending on more or less restrictive definitions of homosexuality. They estimated that, for females, the genetic influence accounted for less than 0.10 , the nonshared environment for 0.50 , and the shared environment for 0.40 of the observed variance. For males, they estimated a much higher genetic influence of 0.45 , a nonshared environment effect of 0.55 , and an almost absent effect of shared environment. Also, in a population-wide twin study in Sweden, Långström et al. (2010) reported 18\% probandwise concordance for males and $22 \%$ for females for any lifetime same-sex partners. They estimated, for females, $0.18-0.19$ of the same-sex sexual behavior variance was explained by genetic factors, $0.64-0.66$ by nonshared environmental factors, with shared-environmental effects accounting for $0.16-0.17$ of the variance. For males, they estimated that genetic effects explained $0.34-0.39$ of the variance, individual environment accounted for 0.61-0.66, and, again, found an absence of shared-environment effects in males. Finally, in a population-wide twin study in Finland, Alanko et al. (2010) reported probandwise concordance of $50 \%$ for males and $47 \%$ for females. They also gave a higher heritability estimate for sexual orienta- tion of 0.45 for females and 0.50 for males, the rest being influenced by a nonshared environment, with an absence of shared-environment effect in both sexes.

Notably, heritability is population specific because it depends on the prevalence among all members of the sampled population; thus, it is not surprising that different studies, based on different populations, have yielded diverse heritability estimates. However, as more researchers replicate studies and findings, results should become more generalizable (Alanko et al. 2010).

Overall, twin studies, despite their large heterogeneity, do suggest human HS to be influenced by a significant genetic component, with a likely larger effect in males than females (Bailey et al. 2000; Alanko et al. 2010; Långström et al. 2010), and with most investigations converging on a high influence of shared (social, educational) environment only in females (Bailey et al. 2000; Långström et al. 2010). However, see Hershberger (1997) for a higher genetic influence in female HS than in males.

Interestingly, a multiple regression pedigree analysis of possible genetic influences on male HS was found to account for a significant 21\% of sexual orientation variance in an Italian population sample of male HS (Camperio Ciani et al. 2004), fairly in agreement with the heritability values obtained from the twin studies just described.

\section{CRITICISMS TO GENETIC MODEL INFLUENCING HS}

Recently, the hypothesis of a genetic influence on human HS has been challenged, advancing a possible sole role for epigenetics in HS (Rice et al. 2012, 2013). Two main reasons given for this are that (1) the estimated MZ twin concordance for HS appears to be too low, and (2) specific genes influencing HS have not yet been determined.

Regarding the latter statement (2), although direct connections to specific polymorphic genes have yet to be uncontroversially determined for HS, we notice that a wide array of phenotypic expressions are hypothesized to 
A. Camperio Ciani et al.

have some genetic influences still await the direct polymorphism identifications. However, the literature has given indications on the possible location of marker loci for a genetic substrate of HS, at least in males. Two linkage studies reported DNA marker loci for male HS on the X chromosome (Hamer et al. 1993; Hu et al. 1995), at the level of the region q28. A later investigation found no such linkage (Rice et al. 1999). However, a meta-analysis of the results across such studies yielded an estimated level of Xq28 allele sharing between HS brothers of $64 \%$ instead of the $50 \%$ expected by chance (Hamer 1999, 2002). In later work, a genomewide scan reported several new autosomal markers for male sexual orientation (Mustanski et al. 2005). These investigators looked at the entire human genome of males who had two or more HS brothers, and found linkage with polymorphisms on three chromosomes-7, 8 , and 10 - that were shared by approximately $60 \%$ of the HS brothers in the study. Later studies also showed extremely skewed X inactivation in mothers of male HS as compared with mothers of heterosexuals, further suggesting an involvement of the X chromosome (Bocklandt et al. 2006), as well as other maternally imprinted polymorphisms on the autosomes (Bocklandt and Hamer 2003). More recently, a new method supplemented linkage analysis by investigating higher resolution genome-wide association of single nucleotide polymorphism with phenotypic traits. The first studies using this method reported nonsignificant results (Ramagopalan et al. 2010; Drabant et al. 2012) with just a relevant, albeit not significant, effect, possibly a result of a low power of the tests, in region q12.3 of chromosome 8 , associated with male HS subjects (Drabant et al. 2012). However, Sanders et al. (2012), in a more recent large and systematic multicenter study (see also Bailey 2014), found a significant association with the region Xq28 and a region in chromosome 8, substantially confirming the earliest findings of Hamer et al. (1993) and the findings, with the earlier methods, by Mustanski et al. (2005) and Bocklandt et al. (2006).

Overall, it seems that most of the present empirical evidence confirm genomic polymor- phisms associated with male HS in at least two loci, including both the $\mathrm{X}$ chromosome and selected autosomes. Interestingly, as discussed below in the section Candidate Mechanisms for Balancing Selection in Male HS, this evidence concurs well with the predictions in Camperio Ciani et al. (2008) obtained by comparing theoretical population-genetics models with population data for male HS.

Concerning the possible doubts on the genetic influence of HS caused by too-low MZ twin concordances, for example, see the above point (1), we have recalled in the section Twin Studies and Estimates of Genetic Heritability that the estimates derived from the presently known population-wide empirical concordances in MZ twins all indicate a measurable genetic influence on HS, although these twin data may not be incompatible also with the epigenetic influences theoretically proposed by Rice et al. (2012, 2013). Notably, a direct estimate of the probandwise concordance in $\mathrm{MZ}$ twins does not appear to indicate the observed concordances to be too low to be consistent with a genetic loading for HS. Because of partial expressivity and penetrance of the underlying genotype, the prevalence of the HS phenotype in the population results from less-than-Mendelian ratios. In these cases, the probandwise concordance in MZ twins (computed as in McGue 1992) depends on the value of: (1) the prevalence of the phenotypic trait (either from genetic or other origin) in the population; (2) the partial expressivity of the genetic factor as a result of a multicausal origin of HS preference in our species, given by the percentage of individuals showing the trait and who carry the genetic factors (Jannini et al. 2010); and (3) the partial penetrance, that is, the proportion of individuals carrying the genetic factors and expressing the phenotypic trait, possibly attributable to epigenetic, developmental, or environmental modifiers (Balthazart 2011). Then, by considering the HS trait as dichotomous for simplicity (i.e., present or absent), and for reasonable values of these three parameters, for instance, in the range $0.06-0.08$ for the prevalence, between 0.3-05 for the expressivity, and $0.3-0.5$ for the penetrance, the probandwise concordance in 
$\mathrm{MZ}$ twins is computed to be in the range between $12 \%$ and 27\% (Camperio Ciani et al. 2014a). These values are well compatible with, or even lower than, the probandwise concordances reported in the MZ twins studies recalled in the section Twin Studies and Estimates of Genetic Heritability (giving ranges 17\%$50 \%$ for HS concordance in males and $21 \%-$ $47 \%$ in females) (Bailey et al. 2000; Alanko et al. 2010; Långström et al. 2010).

\section{POPULATION GENETICS MODELS OF HS}

\section{Candidate Mechanisms for Balancing Selection in Male HS}

The empirical findings recalled in the section Empirical Evidence on Population Patterns Related to HS in Human Populations indicate that male HS is influenced, as mentioned earlier, by both environmental and genetic factors. The empirical evidence suggests that the frequency of HS is too large to be only because of mutation selection, even if a multiplicity of genetic factors might be involved (Gavrilets and Rice 2006; see Yoder 2011). Furthermore, the known population patterns for male HS described in the section Empirical Evidence on Population Patterns Related to HS in Human Populations also suggest that candidate genetic factors are not undergoing directional, stabilizing, or divergent selection in human populations, but rather are under some form of balancing selection, with mixed evolutionary strategies occurring within stable polymorphic populations.

Kin selection has been advanced (Trivers 1974; Wilson 1975; Pillard and Bailey 1998) as a mechanism by which HS males compensate for their reduced fecundity, enhancing their inclusive fitness through investment toward their most immediate relatives, such as nephews and nieces. Because of the rather low normalized fecundity, $\gamma$, of HS males (in the range $0.2<$ $\gamma<0.7$; see the section Fecundity of Male HS), any such avuncularity in HS males should be very pronounced to achieve a true balancing effect. However, most studies, conducted in a number of different populations, have refuted this hypothesis (Bobrow and Bailey 2001; Rah- man and Hull 2005; Forrester et al. 2011, Camperio Ciani et al. 2014b; but see Vasey et al. 2007; Vasey and VanderLaan 2012).

Other candidate balancing mechanisms for male HS are a priori possible. Hereafter, we follow the systematic analysis of Camperio Ciani et al. (2008), denoted CCZ for brevity. The results derived in each case were framed by CCZ against the constraints given by the relevant empirical data highlighted in the section Empirical Evidence on Population Patterns Related to HS in Human Populations to test the compatibility of the models' outputs with the known population patterns for HS.

\section{Genetic Models for Male HS}

After earlier work on the population genetics of male HS (Getz 1993; MacIntyre and Estep 1993), the more recent debate has considered diverse selection mechanisms, including direct selection modes in which the fitness is solely influenced by an individual's genotype, based on overdominance (OD), or sexually antagonistic (SA) selection, and other selection modes for male HS including maternal effects and genomic imprinting, possibly involving epigenetic activity.

Inspired by some of these competing hypotheses, Gavrilets and Rice (2006) and CCZ have studied a number of models for a single diallelic locus at either an autosomal or Xlinked location, and various selection modes in each case, under the assumption of random mating. Their analysis characterized the range of selection parameters guaranteeing a stable polymorphism and the persistence of the trait in the population. The results showed that single-locus models are largely unstable as their parameter ranges are too narrow to allow for stable polymorphism under the normal variability of population conditions. This leads to either fixation or extinction of the genetic factors, contrary to the main stability requirement of the section Empirical Evidence on Population Patterns Related to HS in Human Populations.

Multilocus genetic factors for male HS should therefore be considered, with the empirical constraints suggesting that at least one of 
the components should be X-linked or maternally imprinted. CCZ thus systematically investigated (again, under the hypothesis of random mating) all the relevant (1- and) 2-locus models, that is, involving (AX) one autosomal locus and one X-linked locus, (XX) two X-linked loci for different values of the linkage, or (AA) two autosomal loci. All models in CCZ included tunable effects of possible antagonistic selection, favoring females, but decreasing the fitness of male carriers, by considering normalized average fecundities $\gamma$ and $\alpha$, respectively, for male and female genotypes, within windows of variability such as $0.2<\gamma<0.7$ and $1.0<\alpha<$ 1.8. This analysis yielded the following results.

1. OD, that is, heterozygous advantage in males. In this hypothesis (Hutchinson 1959; Weinrich 1987; MacIntyre and Estep 1993; King et al. 2005; Gavrilets and Rice 2006), a homozygous form would be maintained attributable to a selective advantage in the corresponding heterozygous form in males. As considered in CCZ, such OD mechanism does not coincide with the classical assumption in which heterozygous advantage is manifested in all carriers regardless of sex, because a tunable SA component is always present, the examined genetic factors being favorable to females. Thus, to a value $\gamma<1$ in homozygous males, there correspond values $\gamma^{\prime}>1$ of the average fecundity for heterozygous males, as well as $\alpha>1$ for female carriers. All of these OD models were shown to generate polymorphic equilibria compatible with the stability requirements highlighted in the section Empirical Evidence on Population Patterns Related to HS in Human Populations for male HS. However, despite the SA ingredient they contain, they always account incorrectly for the pedigree asymmetries highlighted in the section Empirical Evidence on Population Patterns Related to HS in Human Populations, as they predict increased fecundities in all pedigree lines and regardless of sex. As fecundity enrichments in the families of male HS seem not to occur in such a generalized way, but only asymmetrically in ma- ternal-line females (see the section Asymmetries in Pedigrees), the OD selection mode should be excluded from the possible maintenance mechanisms for male HS in the population.

2. SA selection. In this hypothesis (Camperio Ciani et al. 2004, 2009; Gavrilets and Rice 2006; Rahman et al. 2008; Iemmola and Camperio Ciani 2009; VanderLaan and Vasey 2011), mothers of male HS have a higherthan-baseline fecundity, so that values $\gamma<$ 1 and $\alpha>1$ are assigned, respectively, to the normalized fecundities of male and female carriers. From the analysis in CCZ, the autosomal SA-AA model was expectedly found unsuitable. However, the mixed 2-locus model AX-SA, with an autosomal and an $\mathrm{X}$-linked allele, and sexually antagonistic selection, emerged as the simplest prototypical population dynamics capable of meeting all the requirements of the section Empirical Evidence on Population Patterns Related to HS in Human Populations. Also, the fully Xlinked XX-SA model was found to be in accordance with such requirements, although less accurately than the AX-SA hypothesis. In both cases, polymorphism stability at low frequency was predicted, with no extinction or fixation of the genetic factors in wide ranges of increased female fecundity and reduced reproductive success of HS males. Both models also describe all the correct pedigree asymmetries in the maternal line of HS males, with a higher-than-patriline frequency of HS in the males and a higher-than-patriline fecundity in the females. Interestingly, a fecundity increase in paternal aunts of heterosexuals, as compared with homosexuals, was also predicted (later observed in empirical data, see the section Asymmetries in Pedigrees, strengthening the heuristic of these models). An interesting variation on the theme of SA selection was recently explored by Barthes et al. (2013), who showed how male HS can evolve through the dynamics of a SA hypergyny factor within a stratified society; although, in such treatment, no asymmetries were investigated. 
3. Other selection modes on male offspring. CCZ have also analyzed a number of other selection mechanisms based on 2-locus AX and AA models. These included (1) maternal effects, accounted for by assuming that the fitness does not depend on the individual's genotype, but rather on the mother's genotype (Blanchard 1997, 2001, 2004). An interesting instance of this effect would be a possible genetic substrate for the induced immunization hypothesized to be at the basis of the FBO effect in the section Fraternal Birth Order Effect (Blanchard and Bogaert, 1996; Blanchard 2001, 2004; Cantor et al. 2002; Bogaert and Skorska, 2011). The analysis in CCZ also included (2) a selection model describing a form of maternal genomic imprinting (Bocklandt and Hamer 2003; Mustanski et al. 2005; Bocklandt et al. 2006), according to which the fitness depends on alleles that are active in a son only if inherited from the mother. This is described by distinguishing two male genotypes depending on the provenience of the gametes. For the same reasons as with the OD models in the above point (2), these further models contain a tunable SA component. The systematic analysis of their propagation and equilibria showed that all such transmission mechanisms behave in an unstable way, leading too easily to extinction or fixation of the genetic factors, and not allowing for the creation of reported pedigree asymmetries. These conclusions suggest, for instance, that a possible genetic influence on the FBO effect cannot, alone, explain the persistence and patterns of male HS in humans.

The models (1) and (2) may involve epigenetic activity as the origin or concurrent cause of the considered maternal effects or genomic-imprinting mechanisms. The recent hypothesis of epigenetic factors influencing HS caused by possible erasure errors for the epi-marks aiding the canalization of sexual differentiation (Rice et al. 2012, 2013), can likewise be accounted for by this framework. The analysis of CCZ adapted to such epigenetic mechanisms shows its instability, a conclusion confirmed also by the mod- eling in Rice et al. (2012). Any such fixated (epi)genetic factors, with no stable polymorphism, would mostly have stochastic expression once diffused into the population, creating a stochastic noise that accompanies the familial patterns and asymmetries established for male HS (see the section Empirical Evidence on Population Patterns Related to HS in Human Populations), contributing to the apparent nonshared environment components for this trait (Bailey et al. 2000; Plomin et al. 2001; Alanko et al. 2010; Långström et al. 2010). Some fixated factors may include SA epigenetic activity with occasional transmission across generations (Rice et al. 2008, 2012, 2013), creating few-generation familial patterns possibly analogous to those produced by the polymorphic SA genetic components in point (2). Further analysis and data focusing on the familial clustering of the HS trait across numerous generations may contribute to clarify and discern between these different and possibly coexisting transmission mechanisms.

\section{Candidate Selection Mechanisms for Female HS}

Also for female HS, although scarcer than for males, the results from twin and populationpattern studies (see the section Empirical Evidence on Population Patterns Related to HS in Human Populations) indicate that, besides environmental factors, there is a nontrivial genetic influence for this trait (Bailey et al. 2000; Alanko et al. 2010; Långström et al. 2010). Because of the differences in pedigree asymmetries and the frequency of transmission, researchers suggested that different genetic factors affect the expression of sexual orientation in females as compared with males (Pattatucci and Hamer 1995; Alanko et al. 2010).

As discussed in the section Fecundity of Female HS, lesbian fecundity might not always have been, in our evolutionary past, as low as currently observed, and might have (almost) matched the heterosexual average levels. This would have made female HS or, indeed, its coexistence with other female behavioral patterns, an evolutionarily neutral trait, for which any 
A. Camperio Ciani et al.

genetic substratum could have persevered and drifted sheltered from natural selection. At present, were female HS fecundity to remain at the low levels suggested by current data (see the section Fecundity of Female HS), the lack of an efficient balancing fecundity effect would imply a disequilibrium producing a progressive reduction of any genetic component for this trait in future generations.

Pattatucci and Hamer (1995), based on their own wide pedigree analysis of female HS, suggested a possible model for female HS entailing a sex-limited, autosomal, dominant genetic factor, with reduced penetrance and a net negative effect on female reproduction $(\alpha<1)$. They suggested that such a model could explain most of their findings about population patterns of female HS, including its less-than-Mendelian observed ratios and higher rates of HS in female compared with male relatives of female HS, the mother-to-daughter transmission with a lack of generation skipping, and the higher rates in daughters than in mothers, as well as the elevated rates in female cousins through paternal uncles (Pattatucci and Hamer 1995; Pattatucci 1998). No modeling, however, has yet been performed to confirm their dynamics in the population, and clarify how it could be maintained/ balanced in the population with $\alpha<1$.

In a recent proposal, Rice et al. (2008) reinterpreted female HS and part of its familial distribution reported in Pattatucci and Hamer (1995) in light of a SA zygotic drive, which is a competition of the paternal Y chromosome, against selected alleles on the $\mathrm{X}$ chromosome, to enhance male vigor $(\gamma>1)$ at the expense of female offspring $(\alpha<1)$. The SA zygotic drive is a form of sexual conflict that would reduce viability of female fetuses because the $\mathrm{Y}$ chromosome, through epigenetic inactivation, would disrupt daughter-specific developmental pathways. In some cases, this could produce female HS $(\alpha<1)$, whereas in others, it may favor female fetus abortion $(\alpha=0)$. An increase of abortion frequency in mothers of lesbians has indeed been observed (Ellis and Blanchard 2001). Such a SA zygotic drive would, in any case, be expected to be temporary, because, although lacking compensatory effects, it would be rapidly repressed by Fisherian sex-ratio selection (see Friberg and Rice 2014).

Rice et al. (2008) indicate such a mechanism could account for some of the asymmetries reported for HS females by Pattatucci and Hamer (1995), showing elevated frequencies of HS in female relatives whose fathers shared the same Y chromosome, as nieces from paternal uncles. The average HS rates reported for paternal aunts would then be compatible with the fact that elevated rates of female HS should be associated to the X-Y combination of the father, rather than the $\mathrm{Y}$ alone. Also, the observed elevated rates of HS in female HS's daughters would be consistent with the paternal epigenetic effects on the X chromosome being sometimes transmitted across generations. The data in Camperio Ciani et al. (2014a), if confirmed, might be however problematic for the hypothesis of a SA zygotic drive for this trait, as elevated rates of HS in all female classes were recorded, unlike with the earlier data in Pattatucci and Hamer (1995).

\section{CONCLUSIONS}

Multiple independent causes, genetic and environmental, concur to establish same-sex preference in humans, with marked differences in the expression of this phenotype in males and females. Empirically observed population patterns, such as frequency distributions, family clustering, pedigree asymmetries, and sibling concordances, point to genetic heritability of HS, indicating a low-prevalence underlying genetic influence in both sexes with a low-penetrance and partial-expressivity genetic influence on both males and females. Further differences also point to a much higher shared (social, educational) environmental influence in female HS.

For male HS, about which there exist adequate population data, the systematic mathematical analysis of the evolutionary propagation mechanisms eliminates the possible Darwinian paradox associated with HS, resolving it within the framework of sexual conflict, suggesting the following conclusions.

1. OD seems excluded from the putative balancing mechanisms of male HS because the 
patterns of generalized increased fecundity that it indifferently generates in all the relatives of HS males are not empirically confirmed.

2. Sexual antagonism for a multilocus factor with at least an X-linked locus is the selection mode providing closest adherence of the models to the empirically known patterns for both HS sexual orientation of males and higher-than-average fecundity for females in their maternal line. These findings point, with a particularly relevant example, to the occurrence of a first well-identified sexually antagonistic character in humans. This perspective may help shift the focus away from male HS preference per se. Rather than concentrating on the sole aspect of the reduced male fitness that it entails, this places male HS within the more general sexual-conflict framework of a genetic trait with genderspecific benefits, which may have evolved by increasing the fecundity of females, and neither disappears nor completely invades the gene pool.

3. The presence of other genetic components that may have evolved to fixation (such as maternal or genomic-imprinting effects, possibly involving epigenetic activity and sexual conflict) cannot be excluded to coexist independently of and in conjunction with the genetic sexually antagonistic factors in point (2). Being fixated, any such factors would be expressed in the population in a mostly stochastic manner and might non-negligibly contribute both to what we presently consider non-shared environment effects. When transmitted through a few generations (Rice et al. 2008, 2012, 2013), their expression may also create some familial patterns possibly resembling the effect of polymorphic genes.

Female HS has not been studied to the same degree as male HS. Although the latter is associated with matrilines, female HS does not yet appear to be associated with certainty with either parental line, although empirical population and pedigree data are still incomplete.
Possible sexually antagonistic (epi)genetic effects and a fecundity compensation, if any, are still to be confirmed, and systematic mathematical modeling has not been performed on this trait.

In conclusion, human HS has likely different inheritance systems in the two genders, although sexually antagonistic effects are likely driving forces for any (epi)genetic HS heritable components affecting their transmission. The imprint of sexual conflict appears well detectable in males, whereas in females it seems clouded by a number of other unresolved questions.

\section{REFERENCES}

${ }^{*}$ Reference is also in this collection.

Alanko K, Santtila P, Harlaar N, Witting K, Varjonen M, Jern P, Johansson A, von der Pahlen B, Sandnabba NK. 2010. Common genetic effects of gender atypical behavior in childhood and sexual orientation in adulthood: A study of Finnish twins. Arch Sex Behav 39: 81-92.

Apostolou M. 2013. The parental choice branch of sexual selection: Re-examining the evolution of mating behavior. J Integr Soc Sci 3: 37-54.

Bagemihl B. 1999. Biological exuberance: Animal homosexuality and natural diversity. Profile, London.

Bailey JM. 2014. Discussion event held in conjunction with the Annual Meeting of the American Association for the Advancement of Science. Chicago, www.aaas.org/ meetings.

Bailey JM, Benishay DS. 1993. Familial aggregation of female sexual orientation. Am J Psychiatry 150: 272-277.

Bailey JM, Pillard RC. 1991. A genetic study of male sexual orientation. Arch Gen Psychiatry 48: 1089-1096.

Bailey JM, Zucker KJ. 1995. Childhood sex typed behavior and sexual orientation: A conceptual analysis and quantitative review. Dev Psychol 31: 43-56.

Bailey JM, Pillard RC, Neale MC, Agyei Y. 1993. Heritable factors influence sexual orientation in women. Arch Gen Psychiatry 50: 217-223.

Bailey JM, Dunne MP, Martin NG. 2000. Genetic and environmental influences on sexual orientation and its correlates in an Australian twin sample. J Pers Soc Psychol 78: 524-536.

Balthazart J. 2011. The biology of homosexuality. Oxford University Press, Oxford.

Bar On B-A. 1994. Engendering origins: Critical feminist readings in Plato and Aristotle. SUNY Press, New York.

Barthes J, Godelle G, Raymond M. 2013. Human social stratification and hypergyny: Toward an understanding of male homosexual preference. Evol Hum Behav 34: 155-163.

Baumeister RF. 2000. Gender differences in erotic plasticity: The female sex drive as socially flexible and responsive. Psychol Bull 126: 347-374. 
A. Camperio Ciani et al.

Bell AP, Weinberg M. 1978. Homosexualities: A study of diversity among men and women. Simon and Schuster, New York.

Blanchard R. 1997. Birth order and sibling sex ratio in homosexual versus heterosexual males and females. Annu Rev Sex Res 8: 27-67.

Blanchard R. 2001. Fraternal birth order and the maternal immune hypothesis of male homosexuality. Horm Behav 40: $105-114$.

Blanchard R. 2004. Quantitative and theoretical analyses of the relation between older brothers and homosexuality in men. J Theor Biol 230: 173-178.

Blanchard R. 2012. Fertility in the mothers of first born homosexual and heterosexual men. Arch Sex Behav 41: 551-556.

Blanchard R, Bogaert AF. 1996. Homosexuality in men and number of older brothers. Am J Psychiatry 153: 27-31.

Blanchard R, Lippa RA. 2007. Birth order, sibling sex ratio, handedness, and sexual orientation of male and female participants in a BBC Internet research project. Arch Sex Behav 36: 163-176.

Blumstein PW, Schwartz P. 1976. Bisexuality in women. Arch Sex Behav 5: 171-181.

Blumstein PW, Schwartz P. 1977. Bisexuality: Some social psychological issues. J Soc Issues 33: 30-45.

Bobrow D, Bailey JM. 2001. Is male homosexuality maintained via kin selection? Evol Hum Behav 22: 361-368.

Bocklandt S, Hamer DH. 2003. Beyond hormones: A novel hypothesis for the biological basis of male sexual orientation. J Endocrinol Invest 26: 8-12.

Bocklandt S, Horvath S, Vilain E, Hamer DH. 2006. Extreme skewing of $\mathrm{X}$ chromosome inactivation in mothers of homosexual men. Hum Genet 118: 691-694.

Bogaert A. 2004. The prevalence of male homosexuality: The effect of fraternal birth order and variations in family size. J Theor Biol 230: 733-770.

Bogaert AF. 2006. Biological versus non-biological older brothers and men's sexual orientation. Proc Natl Acad Sci 103: 10771-10774.

Bogaert AF, Skorska M. 2011. Sexual orientation, fraternal birth order, and the maternal immune hypothesis: A review. Front Neuroendocrinol 32: 247-254.

Bonduriansky R, Chenoweth F. 2009. Intralocus sexual conflict. Trends Ecol Evol 24: 280-288.

Boomsma D, Busjahn A, Peltonen L. 2002. Classical twin studies and beyond. Nat Rev Genet 3: 872-882.

Bullough V. 1998. Alfred Kinsey and the Kinsey report: Historical overview and lasting contribution. J Sex Res 35: 127-131.

Butler AC. 2005. Gender differences in the prevalence of same-sex sexual partnering: 1988-2002. Soc Forces 84: 421-449.

Cáceres C, Konda K, Pecheny M, Chatterjee A, Lyerla R. 2006. Estimating the number of men who have sex with men in low and middle income countries. Sex Transm Infect 82: 3-9.

Camperio Ciani A, Battaglia U. 2014. Implicit measurements of sexual preference in self-declared heterosexual men: A pilot study on the rate of androphilia in Italy. $J$ Sex Med doi: 10.1111/jsm.12565.
Camperio Ciani A, Pellizzari E. 2012. Fecundity of paternal and maternal non-parental female relatives of homosexual and heterosexual men. PLoS ONE 7: e51088.

Camperio Ciani A, Corna F, Capiluppi C. 2004. Evidence for maternally inherited factors favouring male homosexuality and promoting female fecundity. Proc Biol Sci 271: 2217-2221.

Camperio Ciani A, Cermelli P, Zanzotto G. 2008. Sexually antagonistic selection in human male homosexuality. PLOS ONE 3: 1-8.

Camperio Ciani A, Iemmola F, Blecher S. 2009. Bisexuals and not exclusive homosexuals show evidence of the same genetic factors that promote a female fecundity increase on the maternal line. J Sex Med 6: 449-455.

Camperio Ciani A, Fontanesi L, Iemmola F, Giannella E, Ferron C. 2012. Factors associated with higher fecundity in female maternal relatives of homosexual men. J Sex Med 9: 2878-2887.

Camperio Ciani A, Pellizzari E. 2014a. Sexually antagonistic selection explains homosexuality evolutionary conundrum (abstract). In Cooperation and Conflict in the Family Conference. Sydney, February 2-5.

Camperio Ciani A, Battaglia U, Liotta M. 2014b. Societal norms rather than sexual orientation influences kin altruism and avuncularity in tribal Urak-lawoi, Italian and Spanish adult males. J Sex Res (in press).

Cantor JM, Blanchard R, Paterson AD, Bogaert AF. 2002. How many gay men owe their sexual orientation to fraternal birth order? Arch Sex Behav 31: 63-71.

Colcord JC. 1919 Broken homes: A study of family desertion and its social treatment project, pp. 1-212. Gutenberg, Salt Lake City, UT (reprinted in 2008).

Crompton L. 2006. Homosexuality and civilization. Harvard University Press, Boston.

de Waal FBM, Gavrilets S. 2013. Monogamy with a purpose. Proc Natl Acad Sci 110: 15167-15168.

Diamond M. 1993. Homosexuality and bisexuality in different populations. Arch Sex Behav 22: 291-310.

Diamond LM. 2008. Female bisexuality from adolescence to adulthood: Results from a 10-year longitudinal study. Dev Psychol 44: 5-14.

Dörner G, Rohde W, Schott G, Schnabl C. 1983. On the LH response to oestrogen and LH-RH in transsexual men. Exp Clin Endocrinol 82: 257-267.

Drabant EM, et al. 2012. Genome-wide linkage association study of sexual orientation in a large web-based cohort. American Society of Human Genetics Conference (abstract 1957T). San Francisco.

Eckert ED, Bouchard TJ, Bohlen J, Heston LL. 1986. Homosexuality in monozygotic twins reared apart. Br J Psychiatry 148: 421-425.

Ellis L, Blanchard R. 2001. Birth order, sibling sex ratio, and maternal miscarriages in homosexual and heterosexual men and women. Pers Individ Differ 30: 543-552.

Esterberg KG. 1997. Lesbian and bisexual identities: Constructing communities. In Constructing selves. Temple University Press, Philadelphia.

Eubank EE. 1916. A study of family desertion, pp. 1-74. The Department of Public Welfare, University of Chicago Libraries, Chicago. 
Farr RH, Patterson CJ. 2013. Coparenting among lesbian, gay, and heterosexual couples: Associations with adopted children's outcomes. Child Dev 84: 1226-1240.

Forrester D, VanderLaan DP, Parker JL, Vasey PL. 2011. Male sexual orientation and avuncularity in Canada: Implications for the kin selection hypothesis. J Cognit Cult 11: $3-4$.

* Friberg U, Rice WR. 2014. Sexually antagonistic zygotic drive: A new form of genetic conflict between the sex chromosomes. Cold Spring Harb Perspect Biol doi: 10.1101/cshperspect.a017608.

Frisch M, Hviid A. 2006. Childhood family correlates of heterosexual and homosexual marriages: A national cohort study of two million Danes. Arch Sex Behav 35: 533 547.

Garcia-Falgueras A, Swaab DF. 2010. Sexual hormones and the brain: An essential alliance for sexual identity and sexual orientation in pediatric neuroendocrinology. Endocr Dev 17:, 22-35.

Gates GJ, Badget M, Macomber JE, Chambers K. 2007. Adoption and foster care by gay and lesbian parents in the United States. The Williams Institute, Los Angeles.

* Gavrilets S. 2014. Is sexual conflict an "engine of speciation?" Cold Spring Harb Perspect Biol doi: 10.1101/ cshperspect.a017723.

Gavrilets S, Rice WR. 2006. Genetic models of homosexuality: Generating testable predictions. Proc Biol Sci 273: 3031-3038.

Getz WM. 1993. Invasion and maintenance of alleles that influence mating and parental success. J Theor Biol 162: 515-537.

Hamer D. 1999. Genetics and male sexual orientation. Science 285-803.

Hamer D. 2002. Genetics of sexual behavior. In Molecular genetics and the human personality (ed. Benjamin J, et al.), pp. 257-272. American Psychiatric Publishing, Washington, DC.

Hamer DH, Hu S, Magnuson VL, Hu N, Pattatucci AM. 1993. A linkage between DNA markers on the X-chromosome and male sexual orientation. Science 261: $321-$ 327.

Herdt GH. 1997. Same sex, different cultures: Gays and lesbians across cultures, pp. 1-204. Westview, Boulder, CO.

Herek GM, Gillis JR, Cogan JC, Glunt EK. 1997. Hate crime victimization among lesbian, gay, and bisexual adults: Prevalence, psychological correlates, and methodological issues. J Interpers Violence 12: 195-215.

Herek GM, Gillis JR, Cogan JC. 1999. Psychological sequelae of hate-crime victimization among lesbian, gay, and bisexual adults. J Consult Clin Psychol 67: 945-951.

Hershberger SL. 1997. A twin registry study of male and female sexual orientation. J Sex Res 34: 212-222.

Hewlett BS, Hewlett BL. 2010. Sex and searching for children among Aka foragers and Ngandu farmers of central Africa. Afr Study Monogr 31: 107-125.

Hu S, Pattatucci AML, Patterson C, Li L, Fulkner DW, Cherney SS, Kruglyak L, Hamer DH. 1995. Linkage between sexual orientation and chromosome Xq28 in males but not in females. Nat Genet 11: 248-256.

Hutchinson GE. 1959. A speculative consideration of certain forms of sexual selection in men. Am Nat 93: 81-91.
Iemmola F, Camperio Ciani A. 2009. New evidence of genetic factors influencing sexual orientation in men: Female fecundity increase in the maternal line. Arch Sex Behav 38: 393-399.

Jannini EA, Blanchard R, Camperio Ciani A, Bancroft J. 2010. Male homosexuality: Nature or culture? J Sex Med 7: 3245-3253.

Johnson AM, Wadsworth J, Wellings K, Field J. 1994. Sexual attitudes and lifestyles. Blackwell Scientific, Cambridge, MA.

Kendler KS, Eaves LJ. 1989. The estimation of probandwise concordance in twins: The effect of unequal ascertainment. Acta Genet Med Gemellol (Roma) 38: 253-270.

Kendler KS, Thornton LM, Gilman SE, Kessler RC. 2000. Sexual orientation in a US national sample of twin and non-twin sibling pairs. Am J Psychiatry 157: 1843-1846.

King M, Green J, Osborn DPJ, Arkell J, Hetherton J, Pereira E. 2005. Family size in white gay and heterosexual men. Arch Sex Behav 34: 117-122.

Kraemer S. 1991. The origins of fatherhood: An ancient family process. Fam Proc 30: 377-392.

Lamb ME (ed.). 2004. The role of the father in child development. Wiley, Hoboken, NJ.

Långström N, Rahman Q, Carlström E, Lichtenstein P. 2010. Genetic and environmental effects on same-sex sexual behavior: A population study of twins in Sweden. Arch Sex Behav 39: 75-80.

LeVay S. 2011. Gay, straight, and the reason why: The science of sexual orientation. Oxford University Press, Oxford.

Lippa RA. 2006. Finger lengths, 2D:4D ratios, and their relation to gender-related personality traits and the Big Five. Biol Psychol 71: 116-121.

Lukas D, Clutton-Brock TH. 2013. The evolution of social monogamy in mammals. Science 341: 526-530.

Lynch M. 2007. The frailty of adaptive hypotheses for the origins of organismal complexity. Proc Natl Acad Sci 104: 8597-8604.

MacIntyre F, Estep KW. 1993. Sperm competition and the persistence of genes for male homosexuality. Biosystems 31: $223-233$.

Martin N, Boomsma D, Machin G. 1997. A twin-pronged attack on complex trait. Nat Genet 17: 387-392.

May M. 1988. The "problem of duty": Family desertion in the progressive era. Soc Serv Rev 62: 40-60.

McConaghy N, Hadzi-Pavlovic C, Stevens C, Manicavasagar V, Buhrich N, Vollmer-Conna U. 2006. Fraternal birth order and ratio of heterosexual/homosexual feelings in women and men. J Homosex 51: 161-74.

McGue N. 1992. When assessing twin concordance, use the probandwise not the pairwise rate. Schizophr Bull 18: $171-176$.

Mezey NJ. 2008. New choices, new families: How lesbians decide about motherhood, pp. 1-208. Johns Hopkins University Press, Baltimore.

Moran PAP. 1972. Familial effects in schizophrenia and homosexuality. Aust NZ Psychiatry 6: 116-119.

Mustanski BS, DuPree MG, Nievergelt CM, Bocklandt S, Schork NJ, Hamer DH. 2005. A genomewide scan of male sexual orientation. Hum Genet 116: 272-278. 
Mychasiuk R, Gibb R, Kolb B. 2012. Prenatal stress produces sexually dimorphic and regionally specific changes in gene expression in hippocampus and frontal cortex of developing rat offspring. Dev Neurosci 33: 531-538.

Nash G. 2001. The subversive male: Homosexual and bestial images on European mesolithic rock art. In Indecent exposure: Sexuality, society and the archaeological record, pp. 43-55. Cruithne, Oxford.

Ngun TC, Ghahramani N, Sánchez FJ, Bocklandt S, Vilain E. 2011. The genetics of sex differences in brain and behavior. Front Neuroendocrinol 32: 227-246.

Opie C, Atkinson QD, Dunbar RI, Shultz S. 2013. Male infanticide leads to social monogamy in primates. Proc Natl Acad Sci 110: 13328-13332.

Pattatucci AML. 1998. Molecular investigations into complex behavior: Lessons from sexual orientation studies. Hum Biol 70: 367-386.

Pattatucci AML, Hamer DH. 1995. Development and familiality of sexual orientation in females. Behav Genet 25: 407-419.

Patterson CJ, Riskind RG. 2010. To be a parent: Issues in family formation among gay and lesbian adults. J GLBT Fam Stud 6: 326-340.

Pillard RC, Bailey JM. 1998. Human sexual orientation has a heritable component. Hum Biol 70: 347-365.

Pillard RC, Weinrich JD. 1986. Evidence of familial nature of male homosexuality. Arch Gen Psychiatry 43: 808-812.

Plomin R, DeFries JC, McClearn GE, McGuffin P. 2001. Behavioral genetics, 4th ed. Worth, New York.

Posthuma D, Beem AL, de Geus EJC, van Baal G M, von Hjelmborg JB, Iachine I, Boomsma DI. 2003. Theory and practice in quantitative genetics. Twin Res 6: 361-376.

Rahman Q. 2005. The neurodevelopment of human sexual orientation. Neurosci Biobehav Rev 29: 1057-1066.

Rahman Q, Hull MS. 2005. An empirical test of the kin selection hypothesis for male homosexuality. Arch Sex Behav 34: 461-467.

Rahman Q, Collins A, Morrison M, Orrells JC, Cadinouche K, Greenfield S, Begum S. 2008. Maternal inheritance and familial fecundity factors in male homosexuality. Arch Sex Behav 37: 962-969.

Ramagopalan SV, Dyment DA, Handunnetthi L, Rice GP, Ebers GC. 2010. A genomewide scan of male sexual orientation. J Hum Genet 55: 131-132.

Rice G, Anderson C, Risch N, Ebers G. 1999. Male homosexuality: Absence of linkage to microsatellite markers at Xq28. Science 284: 665-667.

Rice WR, Gavrilets S, Friberg U. 2008. Sexually antagonistic "zygotic drive" of the sex chromosomes. PLoS Genet 4: e1000313.

Rice WR, Friberg U, Gavrilets S. 2012. Homosexuality as a consequence of epigenetically canalized sexual development. Q Rev Biol 87: 343-368.

Rice WR, Friberg U, Gavrilets S. 2013. Homosexuality via canalized development: A testing protocol for a new epigenetic model. Bioessays 35: 764-770.

Rieger G, Blanchard R, Schwartz G, Bailey JM, Sanders AR 2012. Further data concerning Blanchard's (2011) fertility in the mothers of firstborn homosexual and heterosexual men. Arch Sex Behav 41: 529-531.
Rosenbluth S. 1997. Is sexual orientation a matter of choice? Psychol Women Q 21: 595-610.

Ruse M. 1988. Philosophy of biology today. SUNY Press, New York.

Rust PC. 1992. The politics of sexual identity: Sexual attraction and behavior among lesbian and bisexual women. Soc Probl 39: 366-386.

Sanders AR, et al. 2012. Genome-wide linkage scan of male sexual orientation. In American Society of Human Genetics Conference (abstract 1957T). San Francisco.

Savin-Williams RC. 2006 Who's gay? Does it matter? Curr Dir Psychol Sci 15: 40-44.

Schwartz G, Kim RM, Kolundzija AB, Rieger G, Sanders AR. 2010. Biodemographic and physical correlates of sexual orientation in men. Arch Sex Behav 39: 93-109.

Sell RL, Wells JA, Wypij D. 1995. The prevalence of homosexual behavior and attraction in the United States, the United Kingdom and France: Results of national population-based samples. Arch Sex Behav 24: 235-248.

Sham P. 2001. Shifting paradigms in gene-mapping methodology for complex traits. Pharmacogenomics 2: 195202.

Sommer V, Vasey PL. 2006. Homosexual behaviour in animals: An evolutionary perspective. Cambridge University Press, Cambridge.

Stein A. 1997. Sex and sensibility: Stories of a lesbian generation. University of California Press, Oakland, CA.

Trivers RL. 1974. Parent-offspring conflict. Am Zool 14: 249-264.

VanderLaan DP, Vasey PL. 2011. Male sexual orientation in independent Samoa: Evidence for fraternal birth order and maternal fecundity effects. Arch Sex Behav 40: 495503.

Vasey PL. 1995. Homosexual behavior in primates: A review of evidence and theory. Int J Primatol 16: 173-204.

Vasey PL, VanderLaan DP. 2012. Sexual orientation in men and avuncularity in Japan: Implication for the kin selection hypothesis. Arch Sex Behav 41: 209-215.

Vasey PL, Pocock DS, VanderLaan DP. 2007. Kin selection and male androphilia in Samoan Fa'afafine. Evol Human Behav 28: 159-167.

Vrissimtzis NA. 1997. Love, sex and marriage in ancient Greece, 3rd ed. Polygrama, Athens, Greece.

Ward IL, Weisz J. 1980. Maternal stress alters plasma testosterone in fetal males. Science 207: 328-329.

Weinrich JD. 1987. Sexual landscapes. Scribner's, New York.

Whisman V. 1996. Queer by choice: Lesbians, gay men, and the politics of identity. Routledge, New York.

Whitman FL, Diamond M, Martin J. 1993. Homosexual orientation in twins: A report on 61 pairs and three triplet sets. Arch Sex Behav 22: 187-206.

Wilson EO. 1975. Sociobiology: The new synthesis. Harvard University Press, Cambridge, MA.

Wright J, ed. 2009. Homosexuality in the U.S., 1998-2000. In The New York Times Almanac, pp. 1-314. Penguin, New York.

Yoder J. 2011. The intelligent homosexual's guide to natural selection and evolution, with a key to many complicating factors. Scientific American, blogs.scientific american.com/guest-blog/2011/06/21. 


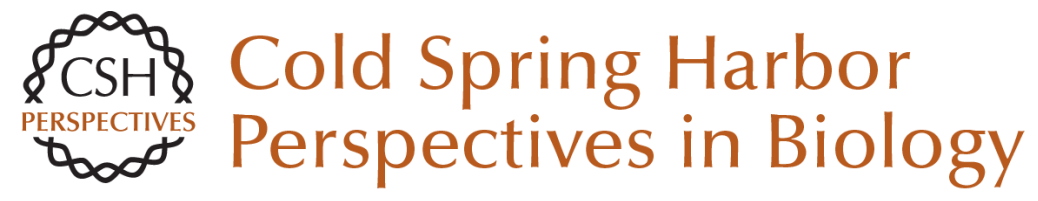

\title{
Human Homosexuality: A Paradigmatic Arena for Sexually Antagonistic Selection?
}

\author{
Andrea Camperio Ciani, Umberto Battaglia and Giovanni Zanzotto
}

Cold Spring Harb Perspect Biol 2015; doi: 10.1101/cshperspect.a017657 originally published online January 29, 2015

\section{Subject Collection The Genetics and Biology of Sexual Conflict}

Mechanisms and Evidence of Genital

Coevolution: The Roles of Natural Selection, Mate

Choice, and Sexual Conflict

Patricia L.R. Brennan and Richard O. Prum

The Evolution of Sexually Antagonistic

Phenotypes

Jennifer C. Perry and Locke Rowe

Reproductive Parasitism: Maternally Inherited

Symbionts in a Biparental World

Gregory D.D. Hurst and Crystal L. Frost

Sex-Biased Gene Expression and Sexual Conflict throughout Development

Fiona C. Ingleby, Ilona Flis and Edward H. Morrow

Human Homosexuality: A Paradigmatic Arena for

Sexually Antagonistic Selection?

Andrea Camperio Ciani, Umberto Battaglia and Giovanni Zanzotto

Sexual Conflict Arising from Extrapair Matings in Birds

Alexis S. Chaine, Robert Montgomerie and Bruce E. Lyon

Sexual Conflict and Seminal Fluid Proteins: A Dynamic Landscape of Sexual Interactions

Laura K. Sirot, Alex Wong, Tracey Chapman, et al.
Infanticide as Sexual Conflict: Coevolution of

Male Strategies and Female Counterstrategies Ryne A. Palombit

Copulatory Wounding and Traumatic Insemination

Klaus Reinhardt, Nils Anthes and Rolanda Lange

Sexual Conflict in Hermaphrodites

Lukas Schärer, Tim Janicke and Steven A. Ramm

Sexual Conflict and Sperm Competition

Dominic A. Edward, Paula Stockley and David J. Hosken

Sexually Antagonistic Zygotic Drive: A New Form of Genetic Conflict between the Sex

Chromosomes

Urban Friberg and William R. Rice

Sex Chromosome Drive

Quentin Helleu, Pierre R. Gérard and Catherine Montchamp-Moreau

Is Sexual Conflict an "Engine of Speciation"? Sergey Gavrilets

For additional articles in this collection, see http://cshperspectives.cshlp.org/cgi/collection/

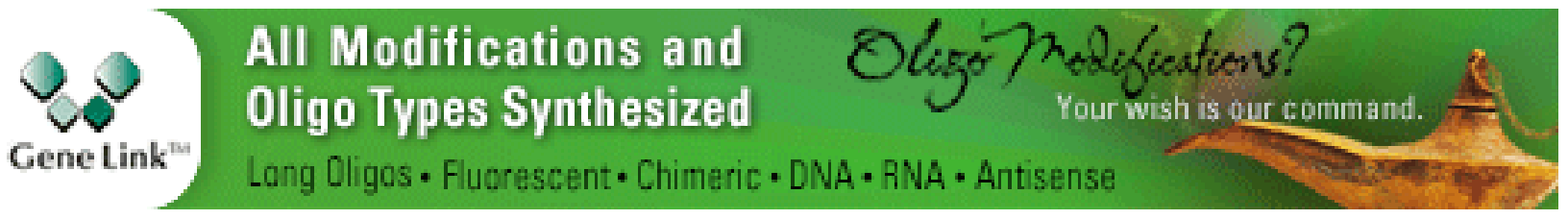

Copyright @ 2015 Cold Spring Harbor Laboratory Press; all rights reserved 
Conflict on the Sex Chromosomes: Cause, Effect, and Complexity

Judith E. Mank, David J. Hosken and Nina Wedell
Sexual Cannibalism as a Manifestation of Sexual

Conflict

Jutta M. Schneider

For additional articles in this collection, see http://cshperspectives.cshlp.org/cgi/collection/

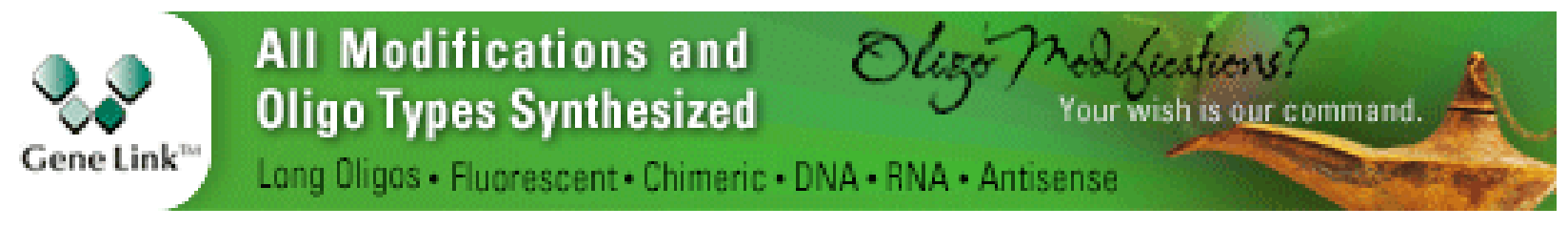

Copyright @ 2015 Cold Spring Harbor Laboratory Press; all rights reserved 